ISSN 2075-4450

www.mdpi.com/journal/insects/

Article

\title{
Tri-Tek (Petroleum Horticultural Oil) and Beauveria bassiana: Use in Eradication Strategies for Bemisia tabaci Mediterranean Species in UK Glasshouses
}

\author{
Andrew G. S. Cuthbertson* and Debbie A. Collins \\ The Food and Environment Research Agency, Sand Hutton, York YO41 1LZ, UK; \\ E-Mail: debbie.collins@fera.gsi.gov.uk \\ * Author to whom correspondence should be addressed; E-Mail: andrew.cuthbertson@fera.gsi.gov.uk; \\ Tel.: +44-0-1904-462-201; Fax: +44-0-1904-462-111.
}

Academic Editor: Brian T. Forschler

Received: 26 November 2014 / Accepted: 9 February 2015 / Published: 12 February 2015

\begin{abstract}
The sweetpotato whitefly Bemisia tabaci (Gennadius) (Hemiptera: Aleyrodidae) is a pest of global importance on both outdoor and glasshouse crops. To date, B. tabaci has not become established in the UK. The UK holds Protected Zone status against this pest and, as a result, B. tabaci entering on plant material is subjected to a policy of eradication. Mediterranean species is now the most prevalent Bemisia species entering the UK. Increasing neonicotinoid resistance is becoming increasingly widespread and problematic with this species. As a result, this continues to pose problems for eradication strategies. The current study investigates the efficacy of Tri-Tek (a petroleum horticultural oil awaiting UK registration) and the fungus Beauveria bassiana to act as control agents against Mediterranean species in UK glasshouses. Tri-Tek provided $100 \%$ egg mortality compared to $74 \%$ for B. bassiana. When tested against second instar larvae, mortalities of $69 \%$ and $65 \%$ respectively were achieved. Both products can be successfully "tank-mixed". A tank-mix application provided $95.5 \%$ mortality of second instar larvae under glasshouse conditions. The potential integration of both products into current Bemisia eradication strategies in UK glasshouses is discussed.
\end{abstract}

Keywords: Bemisia tabaci; chemical; entomopathogenic fungi; eradication 


\section{Introduction}

The sweetpotato whitefly, Bemisia tabaci (Gennadius) (Hemiptera: Aleyrodidae) is regarded as a major pest worldwide [1,2] which causes direct yield loss and economic damage in many commercially important crop species [3-5]. Direct damage is caused by its feeding activity and indirectly due to contamination of leaves with honey dew on which black mould develops and intercepts light, thereby reducing photosynthesis [2].

The pest status of $B$. tabaci insects is complicated by the recognition of 11 well-defined genetic groups and at least 24 morphocryptic species which are morphologically identical but distinguishable at the molecular level [6,7]. The damaging Middle East Asia Minor 1 (MEAM1) species (formerly known as B biotype) is of specific economic concern because it is an effective vector of over 111 viruses from several families, particularly geminiviruses [8], many of which are not present in the UK [9,10].

Bemisia tabaci continues to be regularly intercepted in the UK on imported plant material, mainly associated with poinsettia cuttings [10], where it is subject to statutory controls aimed at eradication [10,11]. In recent years there has been a shift from MEAM1 to Mediterranean species (formerly known as Q biotype) entering the UK [12]. This has led to increased problems in regards to eradication strategies currently employed due to increased chemical resistance shown by B. tabaci Mediterranean. Control of B. tabaci is difficult because of morphological and autecological characteristics (waxy substances on the cuticle, colonisation of the underside of leaves and the rapid development of very dense populations) as well as the ability to develop resistance to a number of pesticides [4,13-17]. Therefore, an integrated programme combining biological, chemical and physical controls is needed if complete eradication is to be reliably achieved. Until recently, in the UK, B. tabaci outbreaks were often treated using the chemicals buprofezin, nicotine, imidacloprid or teflubenzuron [14,18-20]. However, a recent study by Cuthbertson et al. [11] has shown excellent potential of several products (including entomopathogenic fungi) to eradicate $B$. tabaci Mediterranean under controlled laboratory conditions. However, some products (Tri-Tek (petroleum horticultural oil) and Beauveria bassiana) have not been tested under UK glasshouse conditions.

The development of control strategies for non-indigenous insects is limited by UK legislation which precludes the intentional release of quarantine pests into ordinary experimental glasshouses [21]. In the current study, the potential of products (Tri-Tek and Beauveria bassiana) shown to have a high efficacy against B. tabaci Mediterranean species under laboratory conditions [11] were used to test their efficacy against the whitefly under glasshouse conditions using designated quarantine glasshouse cubicles at The Food and Environment Research Agency, York.

\section{Experimental Section}

\subsection{Products and Insect Cultures}

Bemisia tabaci Mediterranean species [12] was cultured under quarantine conditions in perspex cages $(60 \mathrm{~cm} \times 60 \mathrm{~cm} \times 80 \mathrm{~cm}$ ) on poinsettia (Euphorbia pulcherrima Wild. ex Klotzsch c.v Lilo Pink (Euphorbiaceae)) plants as hosts at $23 \pm 1{ }^{\circ} \mathrm{C}$ with a 16:8 h Light:Dark (L:D) regime and an artificial dawn and dusk [22]. The entomopathogenic fungus Beauveria bassiana was supplied as Naturalis from 
Intrachem, Italy. Tri-Tek, a refined petroleum horticultural oil and physically acting product (awaiting UK registration) was supplied by Brandt Ltd. (Springfield, IL, USA).

\subsection{Efficacy against Bemisia tabaci Mediterranean Eggs}

Poinsettia plants (an important UK horticultural commodity) were chosen for testing the efficacy of the two products under glasshouse conditions. Sixteen plants (eight treated and eight control) were infested and incubated as outlined in Cuthbertson et al. [11]. Briefly, four clip cages, modelled on those described by MacGillivray and Anderson [23], were positioned randomly on individual leaves (one cage per leaf) of each of 16 plants (eight treated and eight control). Two male and five female $B$. tabaci were added to each cage and incubated for $48 \mathrm{~h}$ at $25 \pm 1{ }^{\circ} \mathrm{C}, 65 \%$ relative humidity (r.h.) and 16:8 $\mathrm{h}$ Light:Dark (L:D) to allow egg laying, after which adults were removed and infested leaves labelled. After egg laying had occurred (approximately 20-30 eggs produced) and the adults (along with the clip cages) had been removed, the plants were transferred in sealed cooler boxes to the designated glasshouse cubicle. The plants were arranged randomly throughout the cubicle. The conditions of the cubicle were set for $21^{\circ} \mathrm{C}$ (average UK glasshouse temperature [24]). One hour before spraying occurred, the cubicle and plants were soaked with water in order to raise the humidity $(>85 \%)$ [21]. The plants were then sprayed with $B$. bassiana at a rate of $1 \times 10^{7}$ conidia/ml using a hand held Hozelock ${ }^{\circledR}$ Polyspray 2 hand held sprayer with a cone nozzle (Hozelock Ltd., Aylesbury, UK), during late evening on a dull, overcast day. Following spraying, plants remained within the cubicle for a further seven days before being taken back to the quarantine laboratory in sealed cooler boxes for analysis of treatment effect. The procedure was repeated for testing efficacy of Tri-Tek (as a $2 \%$ solution) and also a Tri-Tek and B. bassiana tank-mix $\left(2 \%\right.$ Tri-Tek and $1 \times 10^{7} \mathrm{~B}$. bassiana conidia/mL) against $\mathrm{B}$. tabaci eggs. Previous work has shown that Tri-Tek and B. bassiana can be successfully tank-mixed [11]. Equal numbers of plants were sprayed with water and acted as controls.

\subsection{Efficacy against Bemisia tabaci Mediterranean 2nd Instars}

Following the method above, when infested plants (16 in total; eight treated: eight control) were transferred to the glasshouse cubicle they were further incubated at $25^{\circ} \mathrm{C}$ for another 12 days to allow eggs to hatch and larvae to reach the second larval instar [25-27], the stage most susceptible to fungus infection [28]. The temperature was then lowered to $21^{\circ} \mathrm{C}$ and the cubicle again sprayed with water to raise the humidity to $>85 \%$. Following spraying the plants with $B$. bassiana they remained within the cubicle for a further seven days before being taken back to the quarantine laboratory in sealed cooler boxes for analysis of treatment effect. The procedure was repeated for testing efficacy of Tri-Tek and a Tri-Tek and B. bassiana tank-mix against $B$. tabaci 2 nd instars. The products were applied at the same rates as outlined above.

\subsection{Analysis of Data}

In all trials whiteflies were recorded as dead or alive. Assessments were made using a dissecting microscope. Following Tri-Tek treatment numbers of live and dead Bemisia larvae were recorded after two days. In the case of the fungal treatments and all the Bemisia egg trials, plants were incubated 
for seven days to allow the fungus to germinate and eggs to potentially hatch. Treated eggs were noted as live (hatched larvae) or dead (unhatched). The data underwent non-parametric method testing (Kruskal-Wallis rank sum test and Wilcoxon test) to determine the effect of treatments where necessary.

\section{Results and Discussion}

Bemisia tabaci Mediterranean is the dominant whitefly entering the UK on imported plant material [12]. This whitefly is widely considered to evolve stable resistance to the neonicotinoid insecticides commonly used for Bemisia control more rapidly than MEAM1 [29]. Hence, Mediterranean neonicotinoid resistance is becoming increasingly widespread and problematic, with numerous cases being reported worldwide [30-33]. As a result, this continues to pose problems for eradication programmes in the UK and the maintenance of "Protected Zone" status where eradication of B. tabaci has traditionally centered on the use of neonicotinoids [9]. For eradication programmes to be successful a given treatment must provide total mortality of the pest.

Tri-Tek proved excellent against B. tabaci Mediterranean eggs with $100 \%$ mortality being achieved (Figure 1), significantly better than the water control $(p<0.001)$. Beauveria bassiana provided $74 \%$ egg mortality, significantly less than the Tri-Tek treatment $(p<0.005)$. Tank-mixing the two products also produced $100 \%$ mortality. Interestingly, some eggs did hatch in the Tri-Tek treatments and larvae appeared but these did not develop. They appeared dehydrated and detached from the leaf surface; obviously they were not feeding (Figure 2 ; [34]). Tri-Tek must have been offering some repellent effect or perhaps the young larvae could not penetrate through the residue layer produced by the product in order to feed on the leaf.

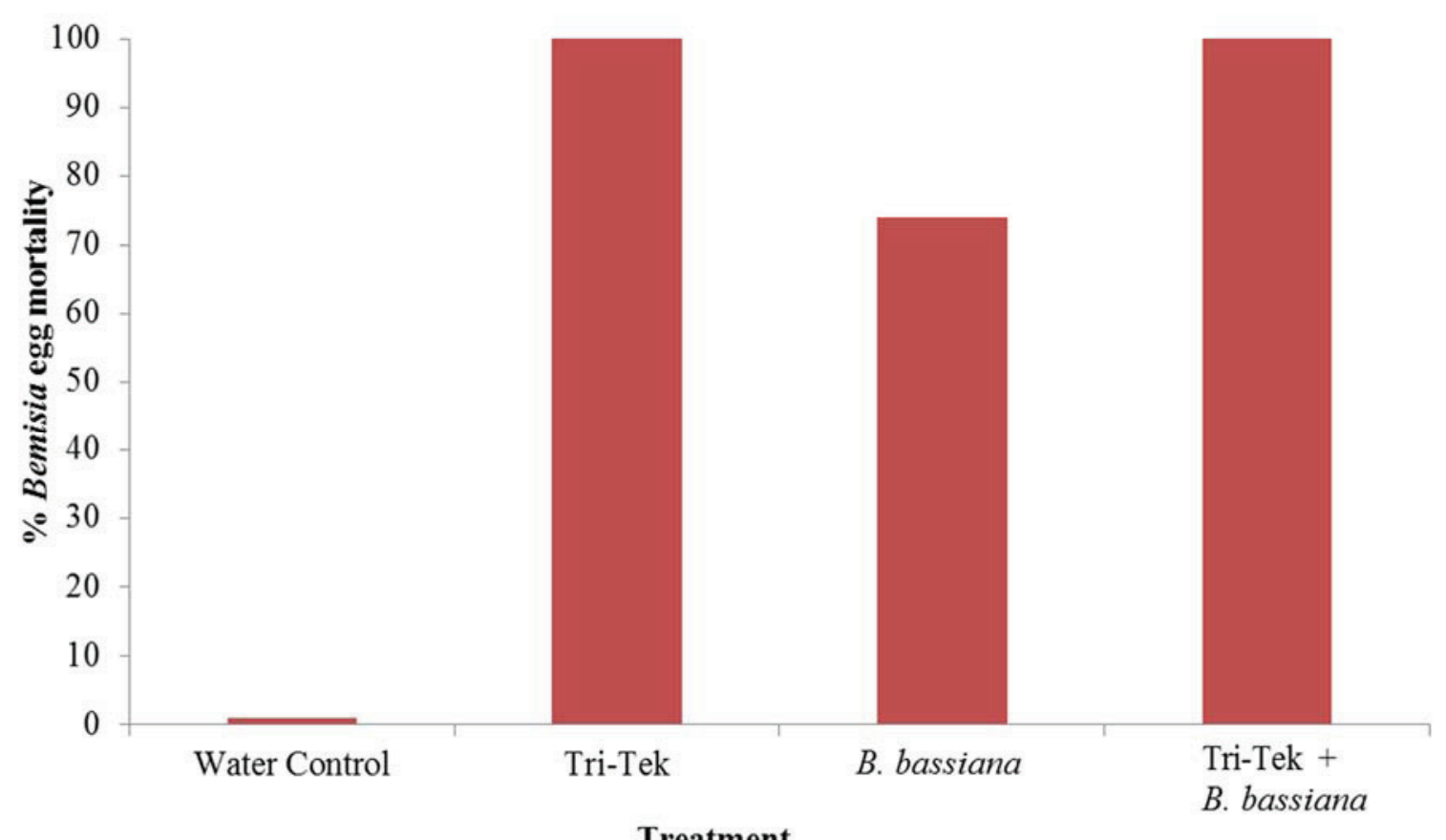

Figure 1. Efficacy of Tri-Tek and Beauveria bassiana and a tank-mix of both products against Bemisia tabaci Mediterranean eggs under glasshouse conditions. Mortality assessed following seven days after treatments. 

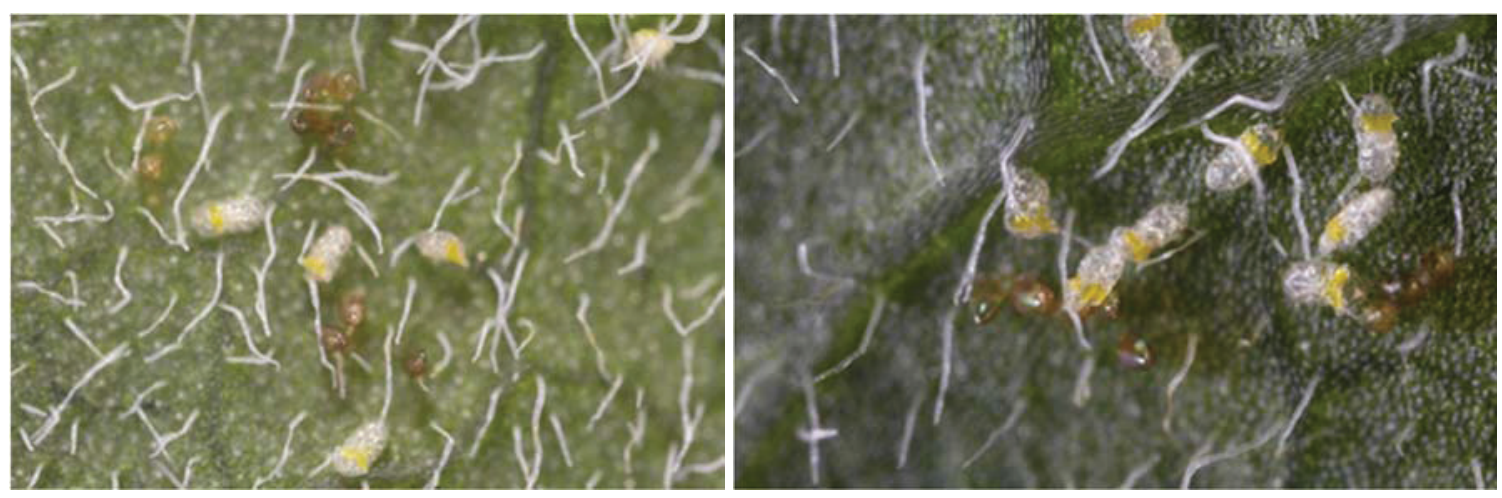

Figure 2. Impact of Tri-Tek on Bemisia tabaci Mediterranean eggs. Some eggs hatched but larvae were detached from leaf surface and subsequently died (Photos: Andrew G. S. Cuthbertson ${ }^{\odot}$ ).

Against 2nd instar B. tabaci Mediterranean larvae Tri-Tek and B. bassiana provided 69\% and 65\% mortality respectively, both significantly higher than the control $(p<0.005)$. Tank-mixing the products increased mortality to $95.5 \%$ (Figure 3); displaying some evidence of a synergistic effect. This may be due to the oil protecting the fungal conidia in some way; perhaps by retaining moisture.

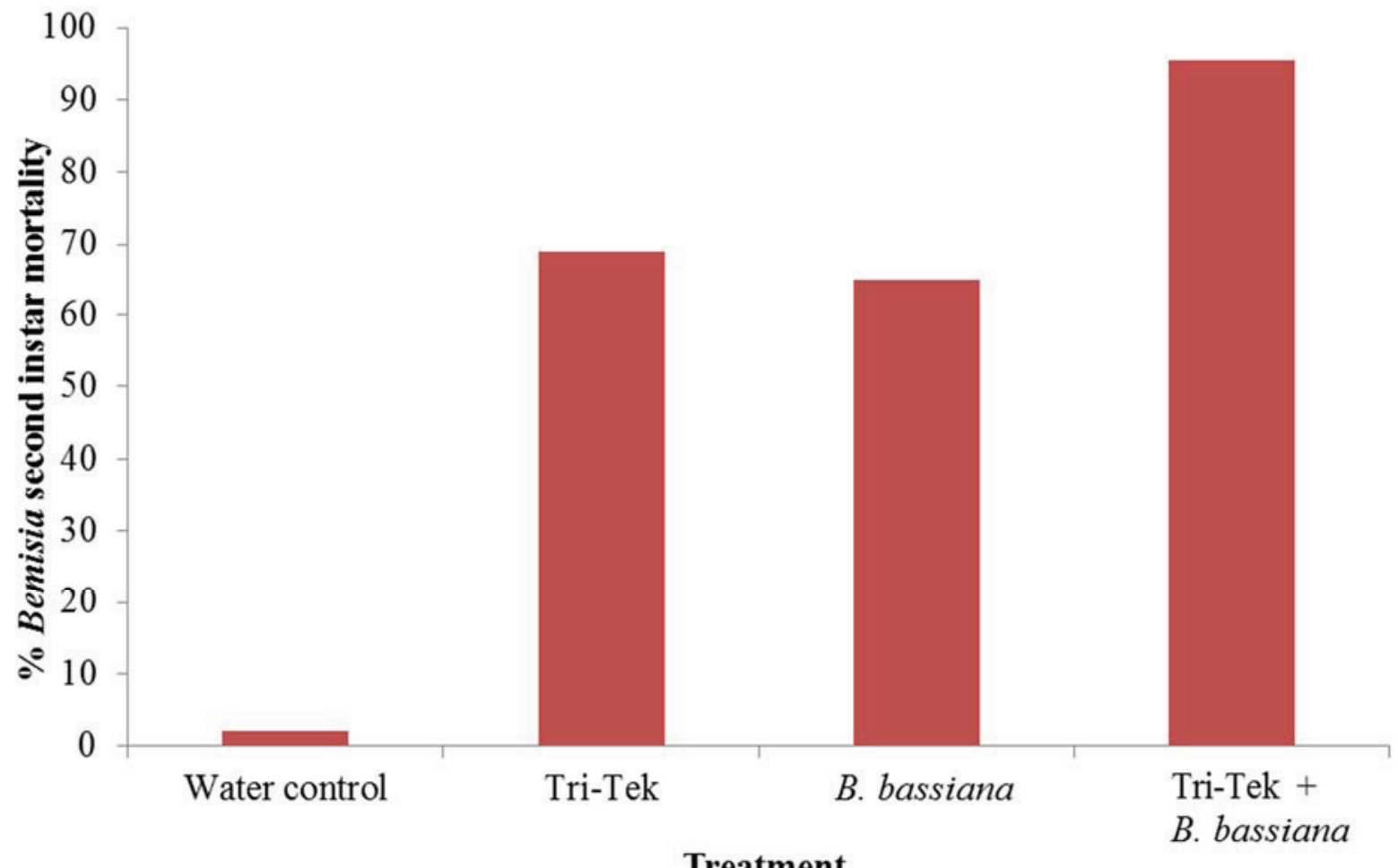

Figure 3. Efficacy of products against Bemisia tabaci Mediterranean second instar larvae. Mortality recorded after two days following treatment with Tri-Tek and after seven days following Beauveria bassiana treatments.

Currently, within the UK, there are protocols that effectively give eradication of Bemisia tabaci Mediterranean species on infected plant produce [11]. Both MEAM1 and Mediterranean can successfully be eradicated through sequential treatments of various products [11]. This study has proven that both Tri-Tek and B. bassiana offer potential to be also used as control agents against $B$. tabaci 
Mediterranean in UK glasshouses. In the current study, as also noted by Cuthbertson et al [11], no phytotoxic effects were noted following the application of Tri-Tek to the poinsettia plants. McKenzie et al. [35] demonstrated that the use of various oils did cause phytotoxic effects on various varieties of poinsettia and recommended that they should be used early in chemical rotation programmes. Further repeated applications of Tri-Tek at various concentrations, and on different plant foliage, would give more valuable information in regards to its suitability for incorporation into eradication strategies. Najar-Rodriguez et al. [36] reports that petroleum spray oils not only act by suffocation but also affect nerve activity of insects and so could be integrated into resistance management strategies for synthetic insecticides that target the central nervous system of insects. The oil could be applied in conjunction with such insecticides to kill resistant individuals that survive the insecticide application. It is unknown if Tri-Tek acts is such a manner.

Upgrading of eradication strategies is essential in order to keep one step ahead of the insect pest in question. An ever increasing scenario facing the UK is that other cryptic species of Bemisia are now also being intercepted on produce [37]. These will no doubt cause problems in regards to ensuring successful eradication in the future.

\section{Conclusions}

Bemisia tabaci remains a severe threat to UK horticulture [10]. The continuing interception of insecticide resistant $B$. tabaci Mediterranean species poses a real challenge in regards to maintaining the UK's Protective Zone status. Beauveria bassiana has shown potential to be included in eradication strategies against B. tabaci. Also, the potential arrival of Tri-Tek onto the UK market provides another tool to be included within current eradication strategies; so helping to ensure the UK remains Bemisia free.

\section{Acknowledgments}

The work on Bemisia tabaci is funded by the Department of Environment, Food and Rural Affairs (Defra), UK.

\section{Author Contributions}

The study was conceived by Andrew G. S. Cuthbertson and Debbie A. Collins. The experimental work was designed and led by Andrew G. S. Cuthbertson who also wrote the manuscript. Both authors read and approved the manuscript.

\section{Conflicts of Interest}

The authors declare no conflict of interest.

\section{References}

1. Landa, Z.; Osborne, L.; Lopez, F.; Eyal, J. A bioassay for determining pathogenicity of entomogenous fungi on whiteflies. Biol. Control 1994, 4, 341-350.

2. Nomikou, M.; Janssen, A.; Schraag, R.; Sabelis, M.W. Phytoseiid predators as potential biological control agents for Bemisia tabaci. Exp. Appl. Acarol. 2001, 25, 271-291. 
3. Gerling, D.; Motro, U.; Horowitz, R. Dynamics of Bemisia tabaci (Gennadius) (Homoptera: Aleyrodidae) attacking cotton in the coastal plain of Israel. Bull. Entomol. Res. 1980, 70, 213-219.

4. Osborne, L.S.; Landa, Z. Biological control of whiteflies with entomopathogenic fungi. Fla. Entomol. 1992, 75, 456-471.

5. Gerling, D., Mayer, R.T., (Eds.). Bemisia: Taxonomy, Biology, Damage, Control and Management; Intercept Limited: Andover, UK, 1996.

6. Dinsdale, A.; Cook, L.; Riginos, C.; Buckley, Y.M.; De Barro, P. Refined global analysis of Bemisia tabaci (Hemiptera: Sternorrhyncha: Aleyrodoidea: Aleyrodidae) mitochondrial cytochrome oxidase 1 to identify species level genetic boundaries. Ann. Entomol. Soc. Am. 2010, 103, 196-208.

7. De Barro, P.J.; Liu, S.S.; Boykin, L.M.; Dinsdale, A.B. Bemisia tabaci: A statement of species status. Ann. Rev. Entomol. 2011, 56, 1-19.

8. Alegbejo, M.D. Whitefly transmitted plant viruses in Nigeria. J. Sustain. Agric. 2000, 17, 99-109.

9. Cuthbertson, A.G.S.; Blackburn, L.F.; Eyre, D.P.; Cannon, R.J.C.; Millar, J.; Northing, P. Bemisia tabaci: The current situation in the UK and the prospect of developing strategies for eradication using entomopathogens. Insect Sci. 2011, 18, 1-10.

10. Cuthbertson, A.G.S. Update on the status of Bemisia tabaci in the UK and the use of entomopathogenic fungi within eradication programmes. Insects 2013, 4, 198-205.

11. Cuthbertson, A.G.S.; Buxton, J.H.; Blackburn, L.F.; Mathers, J.J.; Robinson, K.; Powell, M.E.; Fleming, D.A.; Bell, H.A. Eradicating Bemisia tabaci Q on poinsettia plants in the UK. Crop Prot. 2012, 42, 42-48.

12. Powell, M.E.; Cuthbertson, A.G.S.; Boonham, N.; Morris, J.; Bell, H.A.; Northing, P. First record of the Q Biotype of the sweetpotato whitefly, Bemisia tabaci, intercepted in the UK. Eur. J. Plant Pathol. 2012, 133, 797-801.

13. Prabhaker, N.; Coudriet, D.L.; Meyerdirk, D.E. Insecticide resistance in the sweetpotato whitefly, Bemisia tabaci (Homoptera: Aleyrodidae). J. Econ. Entomol. 1985, 78, 748-752.

14. Sharaf, N. Chemical control of Bemisia tabaci. Agric. Ecol. Environ. 1986, 17, 111-127.

15. Cahill, M.; Byrne, F.J.; Denholm, I.; Devonshire, A.L.; Gorman, K.J. Insecticide resistance in Bemisia tabaci. Pest Sci. 1994, 42, 137-139.

16. Cahill, M.; Gorman, K.; Day, S.; Denholm, I.; Elbert, A.; Nauen, R. Baseline determination and detection of resistance to imidacloprid in Bemisia tabaci (Homoptera: Aleyrodidae). Bull. Entomol. Res. 1996, 86, 343-349.

17. Ahmad, M.; Arif, M.I.; Ahmad, Z.; Denholm, I. Cotton whitefly (Bemisia tabaci) resistance to organophosphate and pyrethroid insecticides in Pakistan. Pest Manag. Sci. 2002, 58, 203-208.

18. Buxton, J.; Clarke, A. Evaluation of insecticide dips to control Bemisia tabaci on poinsettia cuttings. Pest Sci. 1994, 42, 141-142.

19. Cheek, S.; Macdonald, O. Management of Bemisia tabaci. Pest Sci. 1994, 42, 135-137.

20. Cannon, R.J.C.; Eyre, D.; MacLeod, A.; Matthews, L.; Malumphy, C.; Cheek, S.; Bartlett, P.W. Interceptions and outbreaks of Bemisia tabaci in the UK. The BCPC International Congress-Crop Science and Technology 2005. Congress Proc. 2005, 2, 1007-1012.

21. Cuthbertson, A.G.S.; Walters, K.F.A. Pathogenicity of the entomopathogenic fungus Lecanicillium muscarium against the sweetpotato whitefly Bemisia tabaci under laboratory and glasshouse conditions. Mycopathologia 2005, 160, 315-319. 
22. Cuthbertson, A.G.S.; Head, J.; Walters, K.F.A.; Gregory, S.A. The efficacy of the entomopathogenic nematode Steinernema feltiae, against instars of Bemisia tabaci. J. Invertebr. Pathol. 2003, 83, 267-269.

23. MacGillivray, M.F.; Anderson, G.B. Three useful insect cages. Can. Entomol. 1957, 89, 43-46.

24. Cuthbertson, A.G.S.; Mathers, J.J.; Blackburn, L.F.; Korycinska, A.; Powell, M.E.; Luo, W.; Jacobson, R.J.; Northing, P. Population development of Tuta absoluta (Meyrick) (Lepidoptera: Gelechiidae) under simulated UK glasshouse conditions. Insects 2013, 4, 185-197.

25. Butler, G.D.; Henneberry, T.J.; Clayton, T.E. Bemisia tabaci (Homoptera: Aleyrodidae): Development, oviposition, and longevity in relation to temperature. Ann. Entomol. Soc. Am. 1983, 76, 310-313.

26. Bethke, J.A.; Paine, T.D.; Nuessly, G.S. Comparative biology, morphometrics and development of two populations of Bemisia tabaci (Homoptera: Aleyrodidae) on cotton and poinsettia. Ann. Entomol. Soc. Am. 1991, 84, 407-411.

27. Wang, K.H.; Tsai, J.H. Temperature effect on development and reproduction of silverleaf whitefly (Homoptera: Aleyrodidae). Ann. Entomol. Soc. Am. 1996, 89, 375-384.

28. Cuthbertson, A.G.S.; Walters, K.F.A.; Northing, P. Susceptibility of Bemisia tabaci immature stages to the entomopathogenic fungus Lecanicillium muscarium on tomato and verbena foliage. Mycopathologia 2005, 159, 23-29.

29. Nauen, R. Insecticide resistance in European agriculture: Research instead of rumours. The BCPC International Congress - Crop Science \& Technology 2005. Congress Proc. 2005, 1, 123-130.

30. Fernandez, E.; Gravalos, C.; Haro, P.J.; Cifuentes, D.; Bielza, P. Insecticide resistance status of Bemisia tabaci Q-biotype in south-eastern Spain. Pest Manag. Sci. 2009, 65, 885-891.

31. Dennehy, T.J.; Degain, B.A.; Harpold, V.S.; Zaborac, M.; Morin, S.; Fabrick, J.A.; Nichols, R.L.; Brown, J.K.; Bryne, F.J.; Li, X.-C. Extraordinary resistance to insecticides reveals exotic Q biotype of Bemisia tabaci in the new world. J. Econ. Entomol. 2010, 103, 2174-2186.

32. Wang, Z.; Yan, H.; Yang, Y.; Wu, Y. Biotype and insecticide resistance status of the whitefly Bemisia tabaci in China. Pest Manag. Sci. 2010, 66, 1360-1366.

33. Luo, C.; Jones, C.M.; Devine, G.; Zhang, F.; Denholm, I.; Gorman, K. Insecticide resistance in Bemisia tabaci biotype Q (Hemiptera: Aleyrodidae) from China. Crop Prot. 2010, 29, 429-434.

34. Cuthbertson, A.G.S. The Food and Environment Research Agency: Sand Hutton, York, UK. Personal Observation, 2014.

35. McKenzie, C.; Kumar, V.; Palmer, C.L.; Oetting, R.D.; Osborne, L.S. Chemical class rotation for control of Bemisia tabaci (Hemiptera: Aleyrodidae) on poinsettia and their effect on cryptic species population composition. Pest Manag. Sci. 2014, 70, 1573-1587.

36. Najar-Rodriguez, A.J.; Lavidis, N.A.; Mensah, R.K.; Choy, P.T.; Walter, G.H. The toxicological effects of petroleum spray oils on insects - evidence for an alternative mode of action and possible new control options. Food Chem. Toxicol. 2008, 46, 3003-3014.

37. Powell, M.E.; Glover, R; Cuthbertson, A.G.S. Phylogenetic analysis of Bemisia tabaci, intercepted in the UK, based on Mitochondrial Cytochrome Oxidase 1. Bull. Entomol. Res. 2015, in press.

(C) 2015 by the authors; licensee MDPI, Basel, Switzerland. This article is an open access article distributed under the terms and conditions of the Creative Commons Attribution license (http://creativecommons.org/licenses/by/4.0/). 